\title{
EL ARGUMENTO DE LA "CONDUCTA ALTERNATIVA LÍCITA" EN EL DERECHO DE DAÑOS
}

\section{O ARGUMENTO DA "CONDUTA ALTERNATIVA LÍCITA" NO DIREITO DE DANOS}

Fernando Peña López ${ }^{i}$

SUMÁRIO: 1. Introducción. 2. El origen del argumento de la conducta alternativa lícita. 3. El traslado del argumento del comportamiento alternativo lícito al ámbito del derecho de daños. 4. El argumento de la conducta alternativa lícita como instrumento para negar la imputación objetiva. 5. El argumento de la conducta alternativa lícita como instrumento para excluir la «causalidad» en la responsabilidad por omisiones. 5.1. "Causalidad» en las omisiones e imputación objetiva. 5.2. El argumento de la conducta alternativa lícita y la doctrina de la pérdida de oportunidades. 6 . El argumento de la conducta alternativa lícita como instrumento para negar la causalidad de las acciones. 7. Conclusiones. Bibliografía.

\section{INTRODUCCIÓN}

A. D. Virgilio, un trabajador en paro que percibía una prestación por desempleo, obtuvo de la Administración un permiso para salir al extranjero por un periodo máximo de 15 días, lo que implicaba que el día 27 de marzo debía encontrarse de regreso en España. D. Virgilio no estuvo de vuelta en territorio nacional, tras su salida al extranjero, hasta el día 1 de abril de 2009, superando así el período máximo autorizado por la Administración Laboral. En el momento en el que D. Virgilio pretendió la reanudación de la prestación por desempleo se le informó de que su derecho había quedado extinguido por haber permanecido fuera de España más tiempo del autorizado. D. Virgilio, a través del abogado del sindicato, presenta reclamación administrativa previa a la vía laboral, la cual resulta desestimada. El abogado del sindicato prepara posteriormente la demanda que llega incluso a ser firmada por D. Virgilio, pero por causa de algún defecto de organización la demanda nunca llega a presentarse. La Audiencia Provincial de Madrid, resolviendo la acción de responsabilidad interpuesta por D. rgilio frente a su abogado, declara que la decisión de la Administración había sido

\footnotetext{
i Profesor Titular de la Universidad de A Coruña.
} 
correctamente adoptado y que el recurso no tenía posibilidades de éxito, aunque condena al sindicato a indemnizar con $4.000 €$ a D. Virgilio (SAP de Madrid (Sección 25ª) de 25 de marzo de 2015 [EDJ 2015/48293]).

B. La menor, Sara MG, que padecía un asma extrínseco por hipersensibilidad a los neumoalérgenos, y más concretamente a los anfígenos de gato, a los ácaros del polvo y al polen de parietaria, estaba recibiendo un tratamiento a base de inyecciones subcutáneas de un extracto hiposensibilizante de ácaros. Se le habían prescrito dosis estrictas de esta sustancia que debían ser administradas cada dos semanas, aumentando poco a poco en cada uno de estos intervalos temporales. Tras serle inyectadas a la paciente varias dosis sucesivas, el tratamiento se interrumpe durante dos meses y medio. El modo de proceder correcto en esta situación era volver a comenzar el tratamiento en la dosis más reducida. Sin embargo, la ATS María Cristina, en lugar de volver a inyectar a la menor la dosis inicial indicada de 0,05 cc, aplicó una dosis de 0,4 cc, lo cual provocó una reacción anafiláctica en la menor que finalmente determinó una parada cardiorrespiratoria y su muerte. En el proceso penal que se siguió a continuación, se acreditó que la administración de la vacuna entrañaba un riesgo de shock anafiláctico en cualquier caso, y que éste podía producirse también en supuestos de administración de la dosis correcta (SAP de Salamanca de 23 febrero de 2001 [JUR 2001\138410]).

C. En mayo de 1988, en EE.UU., Hewlet Packard, Digital Equipment y otras compañías con un poder de mercado muy relevante fundan la Open Software Foundation (OSP) con el objeto de desarrollar un nuevo sistema operativo alternativo al UNIX de AT\&T que en ese momento dominaba el mercado. Para el desarrollo de ese nuevo sistema operativo, la OSP necesitaba incorporar software de seguridad B-1, y para ello efectúan una solicitud de ofertas en el mercado. Addamax, una compañía que comercializaba software de seguridad acude a la llamada, y presenta su producto a la OSP. En el momento en que este hecho se produce, la OSP y sus miembros eran prácticamente los únicos potenciales compradores del software de seguridad de tipo B-1 y desechan la oferta de Addamax porque su precio es demasiado elevado. Addamax demanda a la OSP, Hewlet Packard y Digital Equipment acusándolos de haber formado un cártel de compras para reducir artificialmente el precio de mercado del software de seguridad, perjudicando gravemente su capacidad de venta. Durante el proceso, el Tribunal de Apelación del 1er. Circuito de Massachussets, declara que, aunque el cártel de compras existiese, el producto ofertado por Addamax era demasiado sofisticado, caro, había llegado tarde y nunca fue capaz de obtener el certificado del National Computer Security Service [Addamax Corp. v. Open Software Found., 152 F.3d 48, 1998 U.S. App. LEXIS 22049, 1998-2 Trade Cas. (CCH) P72, 260 (1st Cir. Mass Sept. 4, 1998)].

En todas las situaciones que se describen en los párrafos anteriores, el demandado podía haber alegado en su defensa el mismo argumento: aunque he realizado una conducta contraria a lo 
que me resultaba exigible, el daño cuyo resarcimiento se solicita se habría producido igualmente aunque me comportase de modo lícito. Si el abogado del sindicato hubiese presentado la demanda, si la ATS hubiera inyectado la dosis prescrita de la vacuna o si Hewlet Packard y Digital Equipment no hubiesen creado un cártel de compras, D. Virgilio habría perdido igualmente el proceso, la menor también habría fallecido y Addamax tampoco hubiese vendido su software. Este argumento, con el que básicamente se pretende conseguir la exoneración de responsabilidad del demandado afirmando la irrelevancia de la ilicitud que tiñe su conducta, se conoce con el nombre de «argumento de la conducta alternativa lícita», o del «comportamiento alternativo conforme a derecho».

Sin embargo, aunque el argumento puede funcionar en cualquiera de los casos anteriores, un buen conocedor del derecho de daños se habrá dado cuenta de que estamos ante supuestos sustancialmente diversos. El primero de los casos expuestos es un ejemplo muy claro de lo que nuestra jurisprudencia actual calificaría como un supuesto de "pérdida de oportunidad»"1, la cual, de conformidad con la mejor doctrina, resuelve problemas de incertidumbre causal ${ }^{2}$. El segundo es un caso en el que la causalidad material está perfectamente acreditada (es obvio que la niña muere por causa de la vacuna que le inyecta la ATS), pero en el que todavía falta por comprobar si existe imputación objetiva entre la conducta y el daño. Por último, el tercero de los casos podríamos calificarlo sin problemas como un caso en el que simplemente no se ha apreciado la existencia de relación de causalidad entre la conducta del demandado y el daño.

¿Cómo es posible que el demandado en un proceso de derecho de daños pueda emplear el mismo argumento para defenderse con éxito en supuestos aparentemente tan diversos? ¿Estamos ante un uso correcto del expediente del comportamiento alternativo lícito en todos estos casos?, y, si fuese así, ¿hay alguna diferencia en el modo en el que debe ser aplicado este argumento en función del tipo de caso ante el que nos encontremos? Estas son algunas de las preguntas que trataré de contestar a lo largo de este trabajo. Para ir desenredando la madeja que nos conduzca a las respuestas que buscamos, entiendo que lo mejor es analizar de dónde procede el argumento del «comportamiento alternativo lícito» o «comportamiento alternativo conforme a derecho». Sabiendo de dónde procede y cuál era su finalidad original será mucho más sencillo averiguar por qué funciona en todos los supuestos que hemos visto, como expediente que justifica la exoneración de responsabilidad de un pretendido responsable.

\section{EL ORIGEN DEL ARGUMENTO DE LA CONDUCTA ALTERNATIVA LÍCITA}

\footnotetext{
1 De hecho es uno de los muchos ejemplos que se emplean en PASQUAU LIAÑO, M.: Valoración crítica de la aplicación jurisprudencial de la doctrina de la pérdida de oportunidades. En: HERRADOR, M. (dir.): Daño, Responsabilidad y Seguro. Madrid: Francis Lefebvre, 2016. p. 488.

2 Vid. v.gr. MARTÍN CASALS, M.: La modernización del derecho de la responsabilidad extracontractual. En: AA.VV. Cuestiones actuales en materia de responsabilidad civil. XV Jornadas de la APDC. Servicio de publicaciones de la Universidad de Murcia. Murcia, 2011. p. 48; MEDINA ALCOZ, L., El nexo causal. La pérdida de oportunidad. En: REGLERO, F.: Tratado de responsabilidad civil. T.I. Cizur Menor: Thomson ReutersAranzadi, 2014. p. 491.
} 
El argumento de la conducta alternativa lícita, o del comportamiento alternativo conforme a derecho, procede de la ciencia del derecho penal. En concreto parece que fue el penalista austríaco FRANZ EXNER el que en 1930, por vez primera, introduce en el debate doctrinal la cuestión de si debía constituir un fundamento para excluir la responsabilidad criminal el hecho de que, si el autor del hecho delictivo se hubiese comportado de modo lícito, el resultado prohibido no se habría producido ${ }^{3}$. Esta discusión se ha mantenido en el derecho alemán desde aquel momento hasta el presente. Se trata de un debate, además, que doctrinalmente ha girado siempre en torno a un grupo de antiguos casos del Reichsgericht (el equivalente a nuestro Tribunal Supremo en Alemania entre 1879 y 1945) que, por su plasticidad, facilitan considerablemente la explicación de los términos de la discusión 4 .

\begin{abstract}
El primero de estos casos es el denominado "caso del farmacéutico" de 1887. El titular de una farmacia expidió a la madre de un niño, tras la presentación de la correspondiente receta médica, un determinado fármaco. Con posterioridad el farmacéutico vuelve a vender a la misma madre ese fármaco cuatro veces más, esta vez sin la necesaria receta. El niño fallece como consecuencia de la ingesta del fármaco. Durante el proceso, el médico declaró que seguramente habría seguido recetando la misma medicina si la madre se la hubiese demandado.
\end{abstract}

El segundo caso, es el llamado "caso de la novocaína" de 1926. Un médico emplea cocaína para anestesiar localmente a un paciente en lugar de la novocaína que debía haberse administrado de acuerdo con la lex artis. El paciente, un niño, muere a consecuencia de la anestesia y su mala condición física. Durante el proceso se prueba que es posible que el niño hubiese fallecido igualmente si se hubiese empleado la novocaína prescrita en el protocolo.

El tercero de los supuestos objeto de debate doctrinal es el "caso de los pelos de cabra" de 1929. El dueño de una fábrica de pinceles compra una remesa de pelos de cabra para introducirlos en su proceso de producción. La normativa de seguridad aplicable le imponía el deber de desinfectar los pinceles y, sin embargo, prescindió de hacerlo, entregándoselos directamente a sus trabajadoras. Como consecuencia del contacto con los pelos de cabra varias trabajadoras fallecieron de ántrax, al verse infectadas por el bacilo del carbunco. En el proceso no se pudo acreditar con seguridad que los gérmenes se hubiesen destruido en caso de que los pinceles se hubieran sometido al tratamiento de desinfección prescrito.

A estos tres supuestos, algo más recientemente, se ha unido otro asunto de 1957 (ya resuelto por el Bundesgerichthof) que se suele conocer con el nombre del "caso del ciclista". En éste, un ciclista es adelantado por un camión sin guardar la distancia de seguridad. El ciclista resulta golpeado por el camión y fallece durante el adelantamiento. Durante el proceso se demostró que el ciclista se encontraba circulando bajo la influencia del alcohol, de modo que, aunque el conductor del camión hubiese mantenido la distancia de seguridad, es probable que el atropello se hubiese producido igualmente.

Toda la doctrina penal alemana y, posteriormente siguiéndola, la española ha considerado siempre que el argumento de la conducta alternativa lícita debía dar lugar a la exoneración de responsabilidad criminal. Sin embargo, nunca se ha llegado a un acuerdo total respecto a su justificación dogmática. Este desacuerdo, sin embargo, no conduce a una divergencia significativa en torno a cómo se resuelven los casos por la doctrina y la jurisprudencia mayoritaria.

\footnotetext{
${ }^{3}$ GIMBERNAT, E.: El comportamiento alternativo conforme a derecho. De la causalidad a la imputación objetiva. Montevideo-Buenos Aires: B. de F., 2017. p. 7.
} 
Dogmáticamente. Aunque en principio hubo quien mantuvo que, en los supuestos de comportamiento alternativo lícito, estábamos ante casos de falta de causalidad material, pronto se abandonó esta posición. En la actualidad nadie en la doctrina penal dudaría de que cualquiera de los cuatro casos que se han expuesto son de homicidio imprudente y que, en todos ellos, la muerte de las víctimas es indudablemente causada por la acción del acusado (el farmacéutico administra el fármaco que la produce, el anestesista suministra la cocaína que la causa, el fabricante de pinceles entrega los pinceles infectados y el conductor del camión golpea al ciclista) ${ }^{5}$. Descartada la causalidad material, la doctrina debatió si considerarlo un elemento de la antijuridicidad, de la causalidad jurídica o de la culpabilidad propia de los delitos imprudentes. Sin embargo, desde la aparición y consolidación de la teoría de la imputación objetiva, la práctica totalidad de la doctrina penal se ha inclinado por esta última tesis 6 . Por consiguiente, hoy es absolutamente mayoritaria la posición que entiende que, en los supuestos de conducta alternativa lícita, estamos ante casos en los que lo que está en juego es la existencia de imputación objetiva entre la conducta del presunto responsable y el resultado prohibido por la norma (en los cuatro casos que consideramos, la muerte).

Sin embargo, dentro de la teoría de la imputación objetiva, todavía no se ha llegado a un acuerdo acerca de cuál es el concreto criterio de imputación objetiva al que debe quedar adscrito el argumento de la conducta alternativa lícita. En este sentido, los autores se han dividido en dos grupos distintos:

\begin{abstract}
A) En primer término están aquellos que defienden la denominada «teoría de la evitabilidad». Estos penalistas entienden que, para poder afirmar la imputación objetiva del resultado prohibido a la acción imprudente del presunto responsable, es necesario que exista una conexión entre la infracción del deber de cuidado y la producción del resultado (la llamada «conexión de la infracción del deber» o «Pflichtwidrigkeitszusammenhang» ${ }^{7}$, o el «nexo de antijuridicidad» $\left.{ }^{8}\right)$. Es decir, para que haya imputación objetiva, el resultado muerte de los casos tiene que haberse producido precisamente porque se ha infringido el deber de cuidado o de diligencia y no por otra causa distinta.
\end{abstract}

B) La segunda teoría que explica el argumento de la conducta alternativa lícita dentro de la teoría de la imputación objetiva es la del «incremento del riesgo». Para los partidarios de esta tesis, sólo existirá imputación objetiva entre la conducta imprudente y el resultado prohibido cuando la primera haya aumentado el riesgo de que se produzca el segundo. O lo que es lo mismo, existe imputación objetiva sólo si la falta de diligencia ha aumentado el peligro de que el resultado se produzca. Si el peligro hubiese sido el mismo en caso de que el presunto responsable hubiese actuado conforme a su deber de cuidado, entonces no hay imputación objetiva.

En la práctica. Las dos teorías o posiciones que se acaban de describir justifican la exoneración de responsabilidad por conducta alternativa lícita con diversos argumentos. La pregunta que surge a continuación es, sin embargo, si además de la diferencia semántica, se deriva alguna

\footnotetext{
${ }^{4}$ Describo los cuatro casos siguiendo a GIMBERNAT, El comportamiento alternativo..., p. 8.

${ }^{5}$ GIMBERNAT, El comportamiento alternativo..., p. 39.

${ }^{6}$ En GIMBERNAT, El comportamiento alternativo..., p. 9-10, se puede encontrar una referencia a los diversos penalistas que se adscribieron a una u otra posición.

${ }^{7}$ GIMBERNAT, El comportamiento alternativo..., p. 15.

${ }^{8}$ Cfr. STS, Sala 2ª , de 12 de junio de 1990 [RJ 1990/5275].
} 
consecuencia del hecho de que se siga la teoría de la evitabilidad o la del incremento del riesgo. La respuesta, a mi modo de ver, es negativa. A la hora de la verdad, la diferencia entre lo que hay que probar en un proceso en el que se aplique la teoría de la evitabilidad o la teoría del incremento de riesgo no es significativa. Como sucede con todos los supuestos en los que es preciso considerar la relevancia de un curso causal hipotético (¿qué habría sucedido en caso de que...?), la decisión acerca de si el argumento de la conducta alternativa licita debe exonerar de responsabilidad o no, es una cuestión de probabilidades. En concreto, depende del factor de probabilidad de que el comportamiento alternativo lícito produzca el mismo resultado que el ejecutado por el demandado que infringe el deber de cuidado-. Obviamente no es lo mismo exigir, para que el argumento de la conducta alternativa lícita tenga éxito, que se demuestre que existía alguna posibilidad de que el resultado fuese idéntico, que requerir una probabilidad del $95 \%$ de que el resultado fuese el mismo. $\mathrm{Si}$ se admite la primera posición, todos los autores de los cuatro casos que estamos considerando serían absueltos, mientras que con la segunda, la absolución, como máximo, sería posible quizá en alguno de los dos primeros.

\begin{abstract}
A) La inmensa mayoría de los autores y de la jurisprudencia ${ }^{9}$ que sigue la teoría de la evitabilidad señala que, para que la alegación del argumento de la conducta lícita alternativa tenga éxito, es preciso que quien la alega pruebe que el resultado prohibido se habría producido también con la conducta lícita «con una probabilidad rayana en la certeza» o «con una alta probabilidad». Sólo así quedará demostrado que, en realidad, no existía esa conexión, que predica la tesis de la evitabilidad, entre la infracción del deber de cuidado y el resultado prohibido.
\end{abstract}

B) El sector doctrinal y jurisprudencial que se manifiesta a favor de la tesis del «incremento del riesgo», sin embargo, aborda el problema desde una perspectiva diferente. Desde esta perspectiva, lo importante es valorar si la producción del resultado prohibido era más probable con una conducta imprudente que con una correcta $^{10}$. Dicho de otra forma, lo que es necesario comprobar es si el presunto responsable, al realizar la conducta imprudente, incrementó las probabilidades de que el resultado se produjese

En el fondo, más allá de la semántica, una y otra tesis requieren lo mismo del acusado que intenta defenderse alegando el argumento objeto de este trabajo: el acusado debe probar que las posibilidades de que se hubiese producido el resultado prohibido hubiesen sido las mismas aunque se hubiese comportado correctamente. Siempre que haya una diferencia de probabilidad mínimamente significativa entre ambas situaciones en favor de la imprudencia o -si se prefiere el término clásico del derecho civil- la negligencia, entonces deberá apreciarse imputación objetiva y, si concurren los demás presupuestos del delito, la responsabilidad criminal ${ }^{11}$.

\footnotetext{
${ }^{9}$ Cfr. v.gr. SSTS, Sala 2a , de 12 de junio de 1990 [RJ 1990/5275\} y de 28 febrero de 1998 [RJ 1998/1197].

10 Cfr. ROXIN, C.: Derecho Penal. Parte General. Fundamentos. La estructura de la teoría general del delito. Traducción de la edic. alemana de 1994. Madrid: Cívitas, 1998, t. I. p. 382-384, SAP de Valencia (Sección 2ª̂) de 11 de mayo de 2011 [JUR 2011\281130].

${ }^{11}$ Sin embargo, existe una posición minoritaria dentro de la teoría de la evitabilidad, de acuerdo con la cual la carga probatoria sería sustancialmente diversa. Este sector, sobre la base del principio «in dubio pro reo» ha defendido que cualquier probabilidad mínimamente significativa de que la conducta alternativa lícita evitaría el resultado prohibido debería sería suficiente para excluir la responsabilidad criminal. Para estos autores, en una situación como ésta, no es seguro (no está «más allá de toda duda razonable») que el resultado prohibido sea
} 
Esta identidad en cuanto a sus consecuencias, entre la posición de la «evitabilidad» y la del «incremento del riesgo» es reconocida tanto por el propio padre de la teoría de la imputación objetiva, el penalista Claus ROXIN ${ }^{12}$, como por el TS en la sentencia del conocido caso del buque Prestige:

\begin{abstract}
"No cabe oponer, con arreglo a la teoría de los cursos causales hipotéticos, que el riesgo de catástrofe ecológica con toda probabilidad o con una seguridad rayana en la certeza, se hubiera producido igualmente aunque el acusado hubiera respetado las reglas de la diligencia debida [...].

Son varios los criterios que se pueden seguir para afirmar la imputación objetiva del resultado: la teoría del incremento del riesgo, la teoría del ámbito de protección de la norma y la teoría de la evitabilidad. Cualquiera de esos criterios de imputación pueden afirmarse en el caso que nos ocupa ya que al actuar como lo hizo y omitir determinados comportamientos ya hemos dicho, incrementó el riesgo de que el vertido se produjese y permaneciera incontrolado" (STS, Sala $2^{\mathrm{a}}$, de 14 de enero de 2015 [RJ 2016(4120] $)^{13}$
\end{abstract}

Sea como fuere, lo importante es retener que, dentro de la tesis dominante en la ciencia y en la jurisprudencia penal, sólo en aquéllos casos en los que no exista una diferencia significativa en las probabilidades de que el resultado se produzca con y sin imprudencia, son susceptibles de producir una absolución por aplicación del argumento de la conducta alternativa lícita. De esta manera, si existían más probabilidades de que los pelos de cabra no desinfectados produjesen la muerte de las trabajadoras que los infectados, el fabricante no podrá exonerarse de responsabilidad alegando el argumento del comportamiento alternativo conforme a derecho. Igualmente, si el hecho de adelantar sin respetar la distancia de seguridad aumentó las posibilidades de golpear al ciclista ebrio, el conductor del camión no podrá alegar la conducta alternativa lícita. Por el contrario, si las posibilidades de que el paciente falleciese al utilizar novocaína como anestésico eran sustancialmente idénticas a las existentes de usarse cocaína, entonces el argumento debía desplegar su virtualidad exoneradora; y lo mismo sucedería si el médico del primer ejemplo asegurase, como sucedió en el caso, que él hubiese seguido expidiendo recetas de habérselo pedido la madre del niño.

\title{
3. EL TRASLADO DEL ARGUMENTO DEL COMPORTAMIENTO ALTERNATIVO LícITO AL ÁMBITO DEL DERECHO DE DAÑOS
}

Los casos resueltos por el Reichsgericht, aunque eran asuntos de derecho penal, también constituyen una referencia dentro del ámbito del derecho de daños alemán. Tanto los casos en sí mismos considerados, como el debate sobre el argumento de la conducta alternativa lícita, terminan por trasladarse en Alemania desde el derecho penal al derecho civil. La diferencia fundamental con

consecuencia de la imprudencia y por lo tanto no es procedente el castigo (vid. GIMBERNAT, El comportamiento alternativo (2017), p. 22-26).

${ }^{12}$ Cfr. ROXIN, Derecho penal..., pp. 383.

13 Puede que por esta razón algunas otras sentencias ni se pronuncian sobre cuál es la tesis a la que se adscriben, cfr. SSTS de 27 de septiembre de 2004 [RJ 2004/6525] y SAP (Sección 23ª) de Madrid de 7 de abril de 2015 [JUR 2015\138000]. 
respecto a lo sucedido en sede penal radica en que, dentro del ámbito del derecho de daños, no existe el acuerdo que hemos visto que hay en el derecho criminal acerca del lugar dogmático al que pertenece el argumento de la conducta alternativa lícita. De todos modos, los especialistas alemanes en derecho de daños, a diferencia de los penalistas, suelen situar mayoritariamente a esta cuestión en la órbita de los problemas que plantea la causalidad material o física.

En este sentido, MARKESINIS y UNBERATH analizan directamente el problema de la conducta alternativa conforme a derecho en el marco de la relación de causalidad material (haftungsbegründende Kausalitat). En efecto, cuando se refieren al caso de los pelos de cabra o al del farmacéutico lo hacen explicándolos como problemas de causalidad que deben resolverse desde de la teoría de la condicio sine qua non ${ }^{14}$. Los problemas de causalidad jurídica (haftungsausfüllende Kausalitat), como la doctrina de la causalidad adecuada o del fin de protección de la norma, se tratan en un lugar completamente distinto de su obra ${ }^{15}$. KOZIOL, por su parte, sitúa la cuestión de la conducta alternativa lícita en el ámbito del problema de los cursos causales hipotéticos. Según este autor, los casos de comportamiento alternativo conforme a derecho son supuestos en los que no es posible imputar un daño a su causante porque existe otro curso causal hipotético alternativo que hubiese producido el mismo daño y en su misma extensión -un curso causal hipotético en el que el causante se comporta lícitamente- ${ }^{-16}$. Algo distinta es la posición de VON BAR, que entiende que en relación con el argumento de la conducta alternativa lícita (rechtmässiges Alternattivverhalten) es imposible distinguir el aspecto causal material -en el sentido de causalidad física-, la cuestión valorativa propia de la causalidad jurídica o imputación objetiva y el problema del daño. Para este autor "todo lo que se decide respecto de una de estas categorías tiene efectos en las otras"17. Según VON BAR, afirmar que el médico que ha empleado la cocaína no responde sólo por falta de causalidad no es posible, al igual que tampoco lo es decir que no responde sólo porque no ha infringido el deber de cuidado.

Tanto la doctrina penal alemana, que sitúa a la cuestión de la conducta alternativa lícita dentro de los problemas propios de la imputación objetiva, como la doctrina civil alemana, que suele localizarla en el ámbito de la relación de causalidad, han dejado sentir su influencia en el derecho español. El argumento de la conducta alternativa conforme a derecho es, claramente, una importación traída de la doctrina alemana, pero, como veremos, no se trata de una importación efectuada de una sola vez. Por el contrario, el argumento ha llegado a nuestro derecho de la

\footnotetext{
14 Véase, por ejemplo, como Markesinis y Unberath mencionan el caso del farmacéutico y el de los pelos de cabra para tratar de problemas relativos al nexo causal dentro de su tratado de derecho de daños; cfr. MARKESINIS, B.; UNBERATH, H.: The German Law of Torts. A Comparative Treatise. Oxford: Hart Publishing, 2002. p. 103.

${ }^{15}$ MARKESINIS, B.; UNBERATH, H. The German Law of Torts..., p. 106 y ss.

${ }^{16}$ Según Koziol, "la fórmula de la condición asegura que ningún daño es atribuido a la esfera de otra persona cuando ese daño hubiese sucedido aunque la otra persona se hubiese comportado de manera distinta" (KOZIOL, H.: Basic Questions on Tort Law from a Germanic Perspective. Viena: Jan Sramek Verlag, 2012. p. 134 - la traducción es mía). Aunque no se refiere expresamente al comportamiento alternativo lícito, KOZIOL analizando un caso similar a los que hemos empleado hasta ahora, sitúa la solución del problema en el marco de los cursos causales hipotéticos en KOZIOL, H.: Austrian report. En: SPIER, J. (edit.): Unification of Tort Law: Causation. London: Kluwer Law International, 2000. p. 19.

${ }^{17}$ Cfr. VON BAR, Ch.: The Common European Law of Torts. Oxford: Oxford University Press, 2005, v. 2. p. 464465.
} 
responsabilidad extracontractual por varias vías distintas, unas procedentes del derecho penal y otras del derecho de daños. El peculiar modo en el que la doctrina alemana ha sido incorporada a nuestro sistema influye en la manera en que el argumento de la conducta alternativa lícita se presenta en el derecho español.

1) Por una parte, tenemos a los autores y a la jurisprudencia que, siguiendo el ejemplo de PANTALEÓN ${ }^{18}$, han traído a nuestro sistema de derecho de daños la teoría de la imputación objetiva desde el derecho penal alemán. Estos autores (v.gr. DíEZ-PICAZO ${ }^{19}$, DE ÁNGEL ${ }^{20}$ ), al igual que la jurisprudencia que les ha seguido ${ }^{21}$, incluyen el criterio del «incremento del riesgo» dentro de los criterios de imputación objetiva. Para todos ellos, este criterio del incremento del riesgo determina que, cuando se pruebe que el daño habría acontecido igual -se habría producido el mismo daño y con la misma extensión- si el causante hubiese desarrollado la conducta correcta, debe excluirse la imputación objetiva y, por lo tanto, la responsabilidad. A excepción de DÍEZ-PICAZO²2, sin embargo, en las obras de este grupo de autores no se emplea la expresión "conducta alternativa lícita» para denominar a este criterio de imputación objetiva ${ }^{23}$. Este sector doctrinal, en pura coherencia con la naturaleza de criterio de imputación objetiva que le atribuye, sitúa al argumento de la conducta alternativa lícita fuera de la cuestión de la causalidad material. La imputación objetiva, como es sabido, constituye un momento posterior a la constatación de la existencia de causalidad material o física. El nexo de causalidad que exige el art. 1.902 CC estaría constituido por un elemento metajurídico: la relación de causalidad material o física, y un elemento jurídico-valorativo: la imputación objetiva, cuyo fin es determinar las causas que son jurídicamente relevantes dentro del llamado «eterno encadenamiento de causas y efectos» 24 .

Este primer grupo de autores, a buen seguro, se sentiría muy cómodo empleando el argumento de la conducta alternativa conforme a derecho en el caso B) de los tres con cuya narración comencé este trabajo (el caso de la menor que falleció como consecuencia de la administración de una dosis de vacuna distinta de la determinada por la lex artis). En ese supuesto, la causalidad material o física está más que demostrada (la niña no habría fallecido si no se le hubiese administrado la vacuna), pero existen dudas acerca de la concurrencia de imputación objetiva (¿fue la dosis incorrecta que le suministró la ATS lo que provocó la muerte?). El problema se resuelve mediante la aplicación de la fórmula de la conducta alternativa conforme a derecho (o del

\footnotetext{
18 PANTALEÓN PRIETO, F.: Comentario del artículo 1.902 del Código Civil. En: AA.VV.: Comentario del Código Civil. Madrid: Ministerio de Justicia, 1991, t. II. p. 1986.

${ }^{19}$ DÍEZ-PICAZO Y PONCE DE LEÓN, L.: Derecho de daños. Madrid: Cívitas, 2000. p. 348-349. Es significativo que Díez-Picazo mencione sólo a Roxin, Mezger y Jakobs, tres penalistas, como únicas fuentes de su exposición de la teoría de la imputación objetiva.

20 DE ÁNGEL, Causalidad en la responsabilidad extracontractual: sobre el arbitrio judicial, la «imputación objetiva" y otros extremos. Madrid: Cívitas, 2014. p. 47.

${ }^{21}$ Cfr. SSTS de 23 febrero de 2001 [RJ 2001/2549], 21 de octubre de 2005 [RJ 2005/8547], 2 enero de 2006 [RJ 2006/129], 18 julio de 2006 [RJ 2006/5345], 17 mayo de 2007 [RJ 2007/3542], 5 noviembre de 2009 [RJ 2010/83], de 9 febrero de 2011 [RJ 2011/1822].

22 Díez-Picazo emplea la expresión "criterio de la conducta alternativa correcta» como alternativa para la denominación «incremento del riesgo», cfr. DíEZ-PICAZO, Derecho de daños..., p. 348

${ }^{23}$ La STS de 4 de marzo de 2009 [RJ 2009/1873], que resuelve el caso Altadis, sobre responsabilidad derivada del suministro de tabaco, también emplea la misma expresión "criterio de la conducta alternativa correcta" porque cita expresamente la obra y el párrafo de Díez-Picazo citados en la nota anterior. Siguiendo a esta sentencia, emplea la misma expresión la STS de 24 febrero de 2017 [RJ 2017/826].
} 
«incremento del riesgo» si se prefiere): si la ATS consigue demostrar que la dosis correcta hubiese terminado igual con la vida de la niña, quedará exonerada de responsabilidad.

2) Por otra parte, MARTÍN CASALS y SOLÉ en $2004^{25}$, mencionando como fuente a KOZIOL, propusieron expresamente aplicar el criterio de la "conducta alternativa conforme a derecho" para resolver un problema causal. Concretamente se trataba de determinar cuándo, en los casos de wrongful birth, podía estimarse que es causa del daño la omisión del facultativo que no informa a la madre, durante el plazo en el que todavía puede optar por que se le practique un aborto, de la existencia de malformaciones en el feto. Estos autores sostienen que: "aplicada a los supuestos de wrongful birth, esta doctrina afirmaría que a pesar de su omisión negligente, el médico no será responsable si se demuestra que, de haber proporcionado de forma diligente la información adecuada, la madre gestante tampoco habría abortado". A partir de aquí, la referencia al argumento de la conducta alternativa lícita se convierte en una mención casi obligada en otros trabajos relativos al mismo problema ${ }^{26}$, e incluso en alguna sentencia ${ }^{27}$. Este sector doctrinal presenta al argumento de la conducta alternativa lícita desconectado de la imputación objetiva, como un instrumento jurídico útil para determinar la causalidad de las omisiones. El argumento permitiría decidir cuándo una omisión en el caso del wrongful birth sería la omisión de un deber de información- es o no es causa de un daño.

Para los autores que han adoptado el criterio de la conducta alternativa lícita como medio para determinar la causalidad en las omisiones, lo natural será resolver aplicando exactamente el mismo criterio el caso A) que propuse al comenzar este artículo (el caso del abogado que no presenta la demanda laboral en plazo). Para saber si la conducta del abogado del sindicato es causa del daño consistente en la pérdida del derecho a la prestación por desempleo de su cliente (D. Virgilio), sólo hay que utilizar el argumento que nos ocupa: ¿habría perdido D Virgilio el derecho al paro igualmente en caso de no presentarse la demanda? Si la respuesta es positiva, entonces es que no hay relación de causalidad entre la omisión del abogado y el daño.

3) Por último, en la doctrina española, REGLERO también sitúa al incremento del riesgo como una fórmula para resolver problemas causales, pero no solo respecto de los comportamientos omisivos, sino en general con respecto a cualquier conducta activa o pasiva. De hecho, este autor asimila el argumento de la conducta alternativa lícita, con la «but for» rule del derecho anglosajón, que no es más que el nombre que recibe en ese derecho nuestra fórmula de la "condicio sine qua non»28. Para REGLERO, el argumento de la conducta alternativa lícita conduce a excluir la relación de causalidad material siempre que se pueda afirmar que, suprimiendo la conducta del pretendido responsable, el daño se habría producido igualmente. No cabe duda de que, desde esta posición, se

\footnotetext{
${ }^{24}$ Cfr., por todos, PANTALEÓN, Comentario del art. 1902..., p. 1981.

25 MARTÍN CASALS, M., SOLÉ, J.: Responsabilidad civil por la privación del derecho a abortar (wrongful birth). Indret, 2/2004, 2004. p. 8.

26 Vid. ROMERO COLOMA, A.Ma․: Las acciones de wrongful birth y wrongful life en el Ordenamiento Jurídico español (especial referencia a la responsabilidad civil médica). Revista Crítica de Derecho Inmobiliario, n. 722 2010 , p. 2559 a 2608 . p. $14 / 15$

${ }^{27}$ Cfr. SAP de Salamanca (Sección 1aㅗ) de 29 noviembre de 2006 [JUR 2007\194526].

28 Cfr. REGLERO CAMPOS, L.F. (Coord.). Tratado de Responsabilidad Civil, 3. ed. Cizur Menor: Thomson Reuters-Aranzadi, 2006. p. 357-359.
} 
puede resolver sin problema el caso C) del primer epígrafe (el caso del cártel de compras) utilizando el criterio que analizamos: si puede afirmarse que la pérdida de beneficios reclamada por Addamax se habría producido con la misma extensión en ausencia de la conducta ilícita -el cártel-, ello significa que la presencia del cártel no ha causado el daño reclamado por Addamax.

En definitiva, el derecho de daños español ofrece un panorama en el que el argumento de la conducta alternativa lícita se presenta, por las razones expuestas, como una fórmula que permite solventar problemas muy diversos -al menos aparentemente- en el derecho de daños. No puede dejar de sorprender que un único argumento sirva a la vez como: a) un test para comprobar la existencia de imputación objetiva entre la conducta y el daño, b) un test para comprobar la existencia de relación de causalidad entre una omisión pura y un daño, y c) un test para comprobar la existencia de relación de causalidad entre una acción o actividad y un daño. La primera duda que surge es, naturalmente, si estamos realmente aplicando el mismo principio cuando el demandado en un proceso sobre derecho de daños alega el argumento con una u otra finalidad; o si detrás de cada uno de esos tres tests se encuentra un trasfondo diferente. La segunda pregunta, conectada con la anterior, es precisamente cuál es esa idea -o ideas- que está detrás de la fórmula de la conducta alternativa lícita; partiendo de la base de que sólo comprendiendo realmente lo que hay detrás del argumento es posible aplicarlo con corrección.

\section{EL ARGUMENTO DE LA CONDUCTA ALTERNATIVA LÍCITA COMO INSTRUMENTO PARA NEGAR LA IMPUTACIÓN OBJETIVA}

Hemos visto que una de las vías por las que el argumento de la conducta alternativa lícita llega al derecho de daños español es de la mano de la teoría de la imputación objetiva. El test del comportamiento alternativo conforme a derecho aparece como una fórmula lógica para constatar la presencia del criterio de imputación objetiva denominado del «incremento del riesgo». La idea que está detrás de la fórmula es la siguiente: si el daño se hubiese producido igual en el caso de que la conducta no hubiese infringido el deber de cuidado, entonces es que la infracción del deber de cuidado (la ilicitud de la conducta) no ha incrementado el riesgo de que el daño se produjese. El razonamiento es fácil de comprender, pero si uno no se queda satisfecho con una mera comprensión superficial en seguida surgen las dudas En efecto, si ya sabemos que el daño lo causó el pretendido responsable (recuérdese que la imputación objetiva actúa cuando la causalidad material ya ha sido comprobada), ¿por qué tiene que haberse incrementado el riesgo de que el daño se produzca? Más aún, ¿cuál es ese riesgo básico que se tiene que haber incrementado?, ¿cómo se determina? Para responder a estas cuestiones y llegar al fondo del significado del argumento de la conducta alternativa lícita en este primer campo de aplicación, es necesario detenerse por un instante en lo que significa la imputación objetiva.

La teoría de la imputación objetiva, con carácter general, afirma que sólo pueden considerarse causas jurídicamente relevantes de un daño aquellas que: a) han creado un riesgo no permitido de que el daño se produzca, siempre que, además, b) el daño sea una concreción de ese 
riesgo no permitido y c) se trate de un daño de los que quería evitar la norma infringida por la conducta del autor ${ }^{29}$.

Toda la teoría, por lo tanto, gira en torno a dos conceptos básicos que deben concurrir para que se pueda producir la imputación objetiva: a) el riesgo o peligro no permitido de que se causen daños y b) la infracción de una norma de cuidado por parte del autor. Si no concurren estos dos requisitos básicos, esto es, si no se ha infringido una norma de conducta por parte del pretendido responsable o si no se ha creado un riesgo no permitido, no se podrá producir la imputación objetiva porque faltará, obviamente, el presupuesto a) o el presupuesto c) de la definición de imputación objetiva. Una vez que se han constatado estos dos requisitos básicos -sobre los que volveré un poco más adelante- todavía será necesario comprobar un último extremo: que el daño que se reclama es precisamente la consecuencia de la creación del riesgo no permitido y de la infracción del deber de conducta. El argumento de la conducta alternativa conforme a derecho es una de las fórmulas lógicas -llamadas «criterios de imputación objetiva»- que permiten asegurarse precisamente de esto último. En efecto, lo que se comprueba con el argumento que nos ocupa es si, en un determinado supuesto, realmente daba igual comportarse licita que ilícitamente -infringir o no infringir el deber de cuidadoporque el daño se habría producido igual y con la misma extensión en uno y otro caso. Si ello fuese así, debe concluirse entonces que el daño no es consecuencia de la infracción del deber de cuidado $y$, por consiguiente, no puede ser imputado objetivamente a la conducta del sujeto.

Pero, si de lo que se trata con el criterio del que estamos hablando es de analizar si la infracción del deber de cuidado tuvo influencia en la producción del perjuicio que se reclama, ¿por qué se llama entonces del «incremento del riesgo»? ¿Cuál es la relación entre esos dos elementos claves de los que hemos hablado: la infracción del deber de cuidado y el riesgo no permitido?

Como tuve ocasión de exponer en otro trabajo ${ }^{30}$, la explicación a la continua mezcla y confusión entre riesgo e infracción del deber de cuidado o, si se prefiere la expresión del derecho civil clásico, entre riesgo y negligencia que se produce dentro del marco de la teoría de la imputación objetiva, es que, en el fondo, se trata de dos caras de la misma moneda. La imputación objetiva es una doctrina construida a partir del concepto clásico de culpa o negligencia. A grandes rasgos, puede afirmarse que lo que hace la teoría de la imputación objetiva es afirmar que de todo el «infinito encadenamiento de causas y efectos» las únicas causas relevantes son aquéllas que se pueden calificar como conductas negligentes de su autor.

Veamos cómo se llega hasta este punto desmenuzando un poco la teoría de la imputación objetiva: la idea de la que parten los penalistas partidarios de la misma es la siguiente: las actividades humanas generan riesgos. Por este motivo, esas actividades muchas veces se concretan en daños a personas y bienes. A pesar de que nadie desea que esos daños se produzcan, el derecho no puede prohibir con carácter general a los seres humanos seguir interactuando en la vida de relación y -por lo tanto- generando riesgos inherentes a dichas actividades. Ahora bien, lo que sí se les exige es que

29 Cfr. DÍEZ-PICAZO, Derecho de daños..., p. 341; PEÑA LÓPEZ, Dogma y realidad del derecho de daños: imputación objetiva, causalidad y culpa en el sistema español y en los PETL. Cizur Menor: Thomson ReutersAranzadi, 2011. p. 25 y ss.

30 Vid. PEÑA LÓPEZ, Dogma y realidad del derecho de daños..., p. 77 y ss. 
lo hagan de tal forma que no aumenten el riesgo que ya existe de por sí de que los daños se produzcan. De este modo, surge la diferencia entre riesgos permitidos y riesgos no permitidos. Cuando alguien supera con su comportamiento el umbral de riesgo permitido y causa un daño, entonces merece que a su conducta se le impute objetivamente ese perjuicio. Si, por el contrario, ha causado daño, pero sin superar ese umbral del riesgo permitido, la consecuencia es que no merece ser responsable. Puede ser ilustrativo recordar, en este sentido, el criterio de imputación objetiva del «riesgo general de la vida», con el que se excluye que pueda existir responsabilidad cuando la conducta dañosa no genera riesgos superiores a los «pequeños riesgos» que todos tenemos que soportar por el hecho de vivir en sociedad.

¿Qué baremo, medida o criterio determina cuándo se supera o se respeta el umbral de riesgo permitido? La respuesta no es otra que el deber de diligencia (o deber de cuidado, como se prefiera). Este deber de cuidado o de diligencia es el que nos informa del modo en que el destinatario de las normas debe comportarse para que el riesgo que crea con su conducta sea un riesgo tolerado o permitido. Por encima del mismo, esto es, cuando se actúa en contra del deber de cuidado- se estará creando un riesgo no permitido y, por consiguiente, si se causa un resultado prohibido, éste será objetivamente imputable a su autor. En palabras de ROXIN, el padre de la imputación objetiva, "lo que excede del riesgo permitido es imprudente" y, por tanto, "el riesgo permitido marca el límite a partir del cual aparece la imprudencia"31. Así pues, al final es la culpa o la no culpa del causante del daño lo que determina si estamos ante un riesgo no permitido y, por ende, su responsabilidad.

Por ejemplo, es bien conocido que el ejercicio de la profesión médica es una importante fuente de riesgos. Obviamente, los extraordinarios beneficios que la sociedad extrae de la práctica de la medicina exigen que ésta, con todos sus riesgos, no sólo se tolere, sino que se fomente activamente. Sin embargo, existe un límite por encima del cual la práctica de la medicina ya no se admite ni tolera porque se entiende que los riesgos que genera son excesivos. ¿Cuál es ese límite? Naturalmente, la lex artis. La lex artis, que no es más que el modo con el que denominamos al deber de diligencia que deben desplegar los médicos, es lo que permite conocer lo que es un riesgo permitido y uno no permitido en el ámbito de la medicina. Toda conducta de un facultativo que sea conforme a la lex artis genera riesgos permitidos, mientras que cualquier conducta que se aparte de ella se considerará generadora de riesgos no permitidos ${ }^{32}$.

¿Cuál es el papel del criterio del «incremento del riesgo» o de la fórmula de la «conducta alternativa lícita» en el entramado de la imputación objetiva? En pura coherencia con el papel de la diligencia debida dentro de esta teoría, lo que se pretende con este criterio es: a) comprobar si se ha infringido el deber de diligencia por parte del pretendido responsable, o lo que es lo mismo, si su conducta ha "aumentado" el riesgo por encima de lo permitido; y b) constatar si el daño que se reclama es una consecuencia de ese "aumento del riesgo" no tolerado. En realidad, aunque estamos empleando otras expresiones distintas (incremento del riesgo, conducta alternativa lícita), estamos

\footnotetext{
${ }^{31}$ Cfr. ROXIN, Derecho penal..., p. 998.

32 Esta misma idea de que la lex artis en el caso de los médicos, o el deber de diligencia con carácter general, es lo que determina el límite entre los riesgos permitidos y los no permitidos está presente, por ejemplo, en la STS, Sala 1a , de 18 de junio de 2013 [RJ 2013\4376].
} 
ante lo que en la doctrina clásica del derecho de obligaciones y contratos se solía conocer como la comprobación de la evitabilidad del daño: ¿se podía haber evitado el daño empleando la diligencia debida? Esto es lo que siempre ha ordenado el art. $1.105 \mathrm{CC}$ al establecer que "nadie responderá de aquellos sucesos que no hubieran podido preverse, o que, previstos, fueran inevitables".

No es difícil comprobar que esta tarea en dos pasos es precisamente lo que realiza el Tribunal Supremo en los casos en los que aplica el criterio del incremento del riesgo o de la conducta alternativa lícita:

\begin{abstract}
En la STS, Sala 1ạ, de 2 de enero de 2006 [RJ 2006/129], el TS aplica el criterio del incremento de riesgo en un caso de accidente aéreo. En concreto se trataba de imputar objetivamente el accidente objeto de la litis a la acción del piloto. Para llevar a cabo la tarea, el TS comprueba primero si se infringió la lex artis por parte del piloto, llegando a una conclusión positiva: "volaba demasiado bajo, con excesiva proximidad a paredes rocosas, en día de viento, que cabía haber apreciado por mera observación, de modo que no se observaban las prescripciones del Reglamento de Circulación aérea". A continuación da el segundo paso determinando que la negligencia del piloto influyó en el resultado, aplicando al "caso el criterio denominado de incremento del riesgo para obtener la conclusión de que, con gran probabilidad rayana en la certeza, sin la actuación del piloto no se daban las condiciones para el accidente".
\end{abstract}

En la STS, Sala 1aㅡ, de 20 de noviembre de 2009 [RJ 2009\7295], el TS sigue el mismo razonamiento, pero en este caso para excluir la presencia de incremento del riesgo. Se trataba de un accidente de tráfico en el que el demandado intentó reducir su responsabilidad alegando una falta de negligencia del conductor de autobús con el que colisionó ("circular a velocidad superior a la autorizada y no hacerlo ceñido a su derecha"). El tribunal admite que la conducción del autobús era negligente (y, por tanto, que estaba creando un riesgo no permitido), pero no cabe la imputación objetiva por «incremento del riesgo» porque: "dadas las características del supuesto de hecho, el accidente se hubiera producido a pesar del exceso de velocidad, salvo que el camión hubiera seguido su trayectoria correctamente por su carril".

En la STS, Sala 1aㅡ, de 9 de febrero de 2011 [RJ 2011/1822], el TS entiende que la infracción de su deber de diligencia por parte de una estación de esquí, colocando un cañón de nieve en un lugar indebido, es lo que sitúa los riesgos creados por la misma fuera de lo permitido, y lo que, a su vez, avala la imputación objetiva del daño: "es un hecho acreditado que [la demandada] instaló un cañón de nieve en un lugar próximo a la pista, lo que, indudablemente, incrementaba el riesgo inherente a la propia práctica del esquí". De cualquier manera, el TS finalmente no aplica la fórmula de la "conducta alternativa lícita», sino la de la adecuación, seguramente porque resultaba evidente que sin el obstáculo la caída no se habría producido nunca: " $Y$ de igual forma es acertado concluir que resultaba previsible que contra dicho elemento colisionaran los esquiadores en caso de las también previsibles, por habituales, caídas durante la práctica de este deporte, aún sin mediar culpa alguna del deportista, como fue el caso".

Como se puede comprobar en todas las resoluciones que acabo de relacionar, el criterio de la "conducta alternativa lícita» se aplica: 1) cuando ya se ha constatado en el asunto que existe causalidad material: el pilotaje del primer caso, la conducción del autobús en el segundo y la colocación del obstáculo en el tercero son todas causas naturales del daño, conforme a la fórmula de la condicio sine qua non; y 2) cuando ya se ha comprobado que todas esas conductas eran negligentes. Apreciada la concurrencia de causalidad física y culpa, se comprueba, mediante el argumento de la conducta alternativa, si esa culpa o negligencia ha influido en la causalidad o si el daño se ha causado con independencia de ella. Para ello, el TS lo que hace es decidir si en el caso 
de que el demandado se hubiese comportado diligentemente habría habido menos probabilidades de que el daño se produjese. En el primer caso entiende que el daño era más probable con el pilotaje negligente que con uno conforme a derecho y condena. En el segundo, por el contrario, entiende que el exceso de velocidad del autobús no aumentaba las probabilidades del daño y, por tanto, excluye la concurrencia de culpas. Finalmente, en el tercero ni siquiera entra a valorar la cuestión al ser evidente que adoptando el cuidado debido -situando el obstáculo en otro sitio- el daño ni siquiera se habría producido.

Sin embargo, no todos los casos de «conducta alternativa licita» o «incremento del riesgo» son tan sencillos de resolver. Piénsese, por ejemplo en el caso con el que inicié este trabajo: el de la ATS que provocaba la muerte de la menor debido a una dosis incorrecta de una vacuna. En este asunto, recordemos que el informe pericial acreditaba que la reacción anafiláctica que produjo el fallecimiento era probable que se produjese también con la dosis correcta. Cuando ello es así, lo que importa no es si el resultado se pudo producir igual cumpliendo la lex artis (algo que sucederá casi siempre en un campo como la medicina) ${ }^{33}$, sino si la conducta negligente incrementó de forma apreciable las posibilidades de que ocurriese el óbito.

Debe tenerse en cuenta, en este sentido, la idea original de toda la teoría de la imputación objetiva: las normas de derecho de daños parten de la idea de que todas las actividades generan riesgos -algunas, como la medicina, muchos más de los ordinarios-, por consiguiente es normal que se produzcan daños, como la muerte de la niña. Lo que pretende impedir la imputación objetiva es que el riesgo de esos daños se incremente indebidamente por las personas -en este caso, por la ATS-. Si se ha producido ese incremento del riesgo porque se ha infringido la lex artis, resulta irrelevante que exista la posibilidad de que el perjuicio se cause también con un comportamiento diligente. Lo único relevante es que, debido a la infracción de la lex artis, el riesgo para la vida de la niña fue más elevado del debido ${ }^{34}$.

Lo que acabo de exponer es lo mismo que explica el TS en su STS, Sala 1a , de 18 de junio de 2013 [RJ 2013\4376]. En el asunto resuelto por esta sentencia, un médico "intentó el parto vaginal tras uno anterior culminado con cesárea, lo que le convertía en un parto de riesgo que los ginecólogos deben conocer e identificar para evitar los problemas que pudieran derivarse, pues ello forma parte de su actividad'. EI TS, que identifica correctamente a esa infracción de la lex artis con un incremento del riesgo no permitido, sabe que el daño se podía producir igualmente aunque se hubiese actuado con diligencia, pero esto no es razón suficiente para excluir la responsabilidad del ginecólogo:

\footnotetext{
${ }^{33}$ Explica Roxin que si entendiésemos que para excluir la imputación objetiva basta con la mera probabilidad de que el resultado se produzca igualmente con la conducta diligente, sería imposible considerar responsable a un cirujano que interviniese a un paciente en una operación muy arriesgada, aunque cometiese groseros errores médicos, cfr. ROXIN, Derecho penal..., p. 381.

${ }^{34}$ Como afirma Gimbernat: "cuando hablamos de riesgo permitido y de riesgo prohibido nos estamos refiriendo a dos distintos niveles de posibilidades o de probabilidades de que una acción produzca un resultado típico [un daño en el caso del derecho de daños]: ejecutando la acción respetuosa del riesgo permitido esas posibilidades están reducidas a un mínimo, mientras que si aquel no se respeta, si lo que se crea es un riesgo prohibido, las posibilidades son mayores o mucho mayores" (GIMBERNAT, El comportamiento alternativo..., p. 50).
} 
"No se ignora que la actividad médica no está desprovista de riesgo y los criterios de objetivación de la responsabilidad profesional sanitaria están vedados por la jurisprudencia, pero lo que no puede el médico es incrementar de forma innecesaria e inadecuada los riesgos que ya en si mismo tiene el acto médico y hacer partícipe de los mismos a la paciente sin una previa y detallada información y consentimiento expreso de esta, cuando era posible hacerlo".

Una última cuestión que quisiera volver a señalar en relación a la imputación objetiva ${ }^{35}$, es que, como ha quedado demostrado con claridad a lo largo de estos párrafos, la culpa o negligencia constituye su ingrediente más importante. Esta circunstancia conduce a que no deban emplearse los criterios de imputación objetiva para determinar la existencia de nexo causal relevante en el marco de los regímenes de responsabilidad objetiva o sin culpa. Aplicar la teoría de la imputación objetiva, el criterio del incremento del riesgo y el argumento de la conducta alternativa lícita hemos visto que implica siempre constatar la infracción de una norma de conducta objetiva (el deber de cuidado o el deber de diligencia), que no es más que lo que los civilistas siempre hemos denominado culpa. $\mathrm{Si}$ queremos mantener a la culpa fuera de un régimen de responsabilidad civil -lo cual, la verdad, es que no es tarea fácil- tenemos que dejar fuera también a la imputación objetiva.

En este sentido, no es de extrañar, por ejemplo que, como ha señalado $A T A Z{ }^{36}$, la jurisprudencia de la Sala $3^{a}$ del TS se haya valido, muchas veces sin mencionarlas expresamente, de la teoría de la imputación objetiva o de la de la causalidad adecuada para «subjetivizar» el régimen de responsabilidad patrimonial -antaño- objetivo de la Administración Pública. No es raro encontrar, en la actualidad en la Sala $3^{\underline{a}}$ de nuestro TS sentencias como la de 7 de marzo de 2012 [RJ 201214662] en la que la apreciación de la causalidad se concreta: "en si se han adoptado o no por la autoridad penitenciaria, las medidas de vigilancia y seguridad necesarias, tendentes a proteger la vida e integridad del recluso fallecido"37.

\section{EL ARGUMENTO DE LA CONDUCTA ALTERNATIVA LÍCITA COMO INSTRUMENTO PARA EXCLUIR LA «CAUSALIDAD» EN LA RESPONSABILIDAD POR OMISIONES}

\section{1. «CAUSALIDAD» EN LAS OMISIONES E IMPUTACIÓN OBJETIVA}

El segundo de los lugares, dentro del campo del derecho de daños, donde hemos visto que un demandado puede alegar con éxito el argumento de la conducta alternativa conforme a derecho es el de la responsabilidad por omisiones. Cuando la actividad del demandado es un mero no hacer (no dar una determinada información, no presentar un recurso, no haber empleado todo el personal necesario o todos los medios necesarios para algo), éste puede emplear el argumento que

${ }^{35}$ Sobre esta cuestión, más ampliamente, vid, PEÑA LÓPEZ, Dogma y realidad..., p. 123 y ss; y GARCíA AMADO, J.A.: Sobre algunos mitos del derecho de daños. Causas que no causan e imputaciones objetivas bastante subjetivas. En: HERRADOR, M. (Dir.): Derecho de daños 2013. Cizur Menor: Thomson ReutersAranzadi, 2013, p. 89 y ss.

${ }^{36}$ ATAZ LÓPEZ, J.: Quince años de jurisprudencia civil y administrativa en materia de daños. En: HERRADOR, M. (dir.): Daño, Responsabilidad y Seguro. Madrid: Francis Lefebvre, 2016. p. 74-79.

37 Vid. la amplia relación de sentencias que se citan en ATAZ, Quince años de jurisprudencia civil y administrativa..., p. 75-79. 
analizamos para excluir su responsabilidad demostrando que, de haber ejecutado la acción debida, el daño se habría producido igualmente.

Esto es lo que sucedió en el caso A) de los que expuse en el primer apartado de este trabajo. En ese asunto, para conocer si la mera omisión del abogado del sindicato que no presento la demanda en plazo, es causa del daño sufrido por D. Virgilio, el juez se preguntó mentalmente si ejecución de la conducta debida por el abogado -la presentación en plazo de la demanda- hubiese conseguido evitar el daño que D. Virgilio reclamaba en el proceso. Si la respuesta a esa pregunta fuese positiva, el abogado podría considerarse causante del daño sufrido por D. Virgilio y viceversa.

Se trata de una situación muy similar a la que hemos estado considerando en el apartado anterior: aquí también existen dos cursos causales, uno real (lo que ha sucedido) y uno hipotético (lo que habría sucedido si el demandado hubiese actuado diligentemente), y de lo que se trata es de comprobar si en ambos casos el resultado hubiese sido el mismo o no. Sin embargo, existe una diferencia importante entre la situación que se da en los casos de imputación objetiva y los que ahora tenemos entre manos, y es que en la situación que contemplamos ahora uno de los dos cursos causales hipotéticos se produce enteramente sin la intervención del pretendido responsable. El supuesto dañador, en este caso, se limita a no hacer nada, por lo que el daño, desde el punto de vista de la causalidad material o empírica, aparece totalmente desconectado de su actuación.

En efecto, constituye casi un lugar común en la doctrina del derecho de daños, el reconocimiento de que en las omisiones no es posible la causalidad conforme a las leyes de la naturaleza ${ }^{38}$. Como refleja el conocido aforismo «ex nihilo nihil fit», las ciencias naturales no pueden atribuir a una omisión el más mínimo efecto causal; pues la relación natural de causa-efecto exige una liberación de energía, una "fuente de energía real que sea capaz de producir un esfuerzo"39 y una omisión, por definición, es una falta de esfuerzo o de energía.

Sin embargo, en el derecho de daños español, como sucede en todos los derechos de daños de nuestro entorno, la ley dice que las omisiones pueden causar daños. Así lo establece el art. 1.902, por lo que no queda más remedio que construir un concepto de causalidad impropio -en el sentido de no empírico- para ellas. Este concepto de causalidad impropia, típica de las omisiones, está formado en la doctrina legal de todos los derechos de nuestro entorno -con mínimas diferencias entre ellos- por dos elementos distintos:

a) La presencia de un deber positivo de actuar a cargo del pretendido responsable. Es lo que en el common law se conocen como affirmative duties ${ }^{40}$, y en derecho penal, «posiciones de garante». Se trata de definir en qué situaciones y/o posiciones tiene una persona que intervenir activamente para prevenir o evitar el peligro de que un tercero sufra daños. No estamos ante un problema sencillo, puesto que como ha

\footnotetext{
${ }^{38}$ Cfr. v.gr. SALVADOR CODERCH, P.: «Causalidad y responsabilidad». InDret, v. 1, p. 1-27, 2000. p. 8.

39 Cfr. JESCHECK, H-H.: Tratado de Derecho penal. Parte General. Traducción de la 5. ed. alemana de 1996. Granada: Comares, 2002. p. 666.

40 Vid. V.gr. los \$§.37-44 del Restatement (Third) of the Law of Torts (Physical and Emotional Harm). En ellos se parte de la regla general de que no hay responsabilidad por las omisiones: "an actor whose conduct has not created a risk of physical or emotional harm to another has no duty of care to the other unless a court determines that one of the affirmative duties provided in $\$ \S .38-44$ is applicable", y con posterioridad se señalan las situaciones enlas que existe un deber de actuar (affirmative duty) para impedir el daño que puede sufrir una persona que está: "at risk of harm due to other forces".
} 
afirmado VON BAR, resulta evidente que "no todo individuo tiene el deber de salvar a todo el mundo de cualquier posible peligro", y que "un suceso que ocurre sin la intervención de una persona generalmente no es susceptible de generar responsabilidad para ese sujeto" 41 . Expone VAN DAM que en el derecho europeo de daños las fuentes principales de "deberes afirmativos" o "posiciones de garante" son la relación existente con la víctima (v.gr. personas respecto de las que existe un deber de información, seguridad o cuidado), con el causante positivo del daño (v.gr. dependientes del omitente), con el objeto en movimiento que produjo el perjuicio (v.gr. las sustancias o radiaciones provenientes de la propiedad del omitente) y con el lugar del accidente (v.gr. la titularidad de las instalaciones fabriles en las que se produjo el accidente $)^{42}$. De cualquier modo, se trata de una cuestión compleja ${ }^{43}$ que se escapa del objetivo de este trabajo. En el caso de D. Virgilio, por lo demás, el deber de actuar del abogado era evidente, dada la relación de servicios profesionales que mantenía con D. Virgilio.

b) Un test de carácter valorativo e hipotético para comprobar la causalidad: La constatación de que añadiendo al curso causal la conducta debida, no se hubiese producido el daño que se reclama ${ }^{44}$.

Es este segundo requisito el que ahora nos interesa, porque es con él con el que está relacionado el argumento de la conducta alternativa lícita. Como se habrá podido apreciar, el requisito constituye una especie de formulación inversa de la condicio sine qua non. Una fórmula invertida porque, mientras que con la regla de la condicio sine qua non se suprime mentalmente la conducta del supuesto responsable para ver si el daño se produciría igualmente, aquí sucede lo contrario: la conducta del pretendido responsable se añade al curso causal. Mediante esta fórmula invertida de la condicio se persigue constatar que el curso causal se habría -hipotéticamente- interrumpido de haber actuado el omitente y, por lo tanto, que el daño no se habría producido.

Así pues, la responsabilidad por omisiones depende, en definitiva, de que el omitente de la conducta debida hubiese podido evitar el daño ejecutando dicha conducta. Simplemente así, a primera vista, nadie podrá negar que, formulada de esta manera, el segundo requisito de la causalidad en las omisiones tiene bastante parecido con el argumento de la «conducta alternativa licita» que forma parte de la teoría de la imputación objetiva. La pregunta es: ¿existe alguna diferencia? Porque lo cierto es que podría haberla si se piensa que cuando empleamos el argumento de la conducta alternativa lícita en la imputación objetiva ya sabemos que el supuesto responsable ha causado el daño (este es nuestro punto de partida), y lo que queremos valorar es si la negligencia del demandado ha tenido algo que ver con ese perjuicio. Por el contrario, en el ámbito de la causalidad en las omisiones parece que buscamos una cosa completamente distinta: perseguimos demostrar que el "no hacer nada", la omisión del demandado es la que ha causado el daño.

Sin embargo, más allá de la pura semántica, y de la obvia diversidad de puntos de partida (en un caso el supuesto responsable ha causado materialmente el daño y en el otro no ha hecho nada), el argumento que empleamos para "imputar" la responsabilidad a uno y a otro es exactamente el mismo: de lo que se trata es de comprobar si el daño (causado o no por el demandado) podía

\footnotetext{
41 VON BAR, The Common European Law of Torts..., p. 219 (la traducción es mía).

42 VAN DAM, C.: European Tort Law. 2. ed. Oxford: Oxford University Press, 2013. p. 248-249.

${ }^{43}$ Así lo reconoce en la doctrina española, YZQUIERDO TOLSADA, M. Responsabilidad civil extracontractual: Parte General. Madrid: Dydinson. 2015. p. 138-139.

${ }^{44}$ En palabras de JESCHECK: "si no cabe imaginar la acción omitida sin que el resultado desaparezca"; cfr. JESCHECK, H.H.: Tratado de Derecho Penal..., p. 666 y 667.
} 
haber sido -hipotéticamente- evitado con la realización de la conducta debida. En el siguiente cuadro, trato de representar gráficamente la operación lógica que se realiza en ambas situaciones:

a) Imputación objetiva

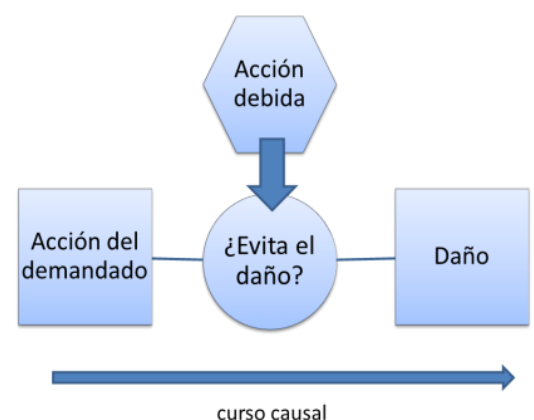

b) Causalidad en las omisiones

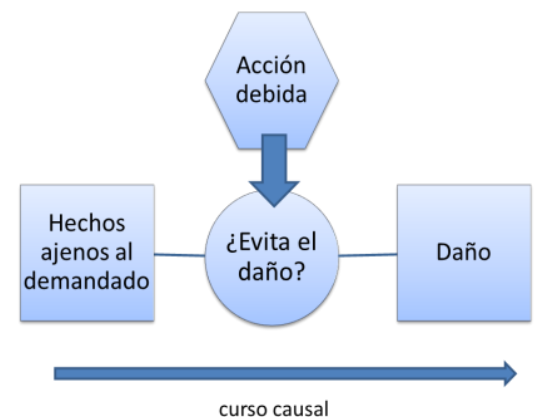

En definitiva, la causalidad en las omisiones se determina mediante una operación lógica, que coincide exactamente con el argumento de la conducta alternativa lícita que estamos analizando: ¿se hubiese evitado el daño con la conducta debida? Empleando los términos de la teoría de la imputación objetiva, podríamos decir que se entiende que la omisión es causa del daño cuando ha «incrementado el riesgo» de que el daño se produzca. De hecho, tanto PANTALEÓN como DíEZPICAZO proponen expresamente a la teoría del incremento del riesgo como la adecuada para determinar la causalidad en las omisiones ${ }^{45}$.

La identidad entre la operación lógica que implica el argumento de la conducta alternativa lícita en el ámbito de la imputación objetiva y en relación con la causalidad en las omisiones provoca que el TS, en la práctica, nunca sienta la necesidad de distinguir conceptualmente entre acciones y omisiones. Así, para el alto tribunal, el incremento del riesgo, la infracción del deber de diligencia y existencia de un deber positivo de actuar son un mismo problema y, a partir de aquí, una vez entiende que concurre esa "genérica" infracción de un deber, aplica el argumento que nos ocupa para resolver el asunto:

En la STS, Sala 1aㅡ, de 17 de mayo de 2007 [RJ 2007/3542], el TS estima que la omisión del demandado, consistente en no haber retirado el arma de los vigilantes jurados una vez terminada la jornada de servicio, es una infracción de su deber de diligencia y ha incrementado el riesgo de que se produjese una muerte por disparos de una de tales armas. El TS declara que: "si la entidad demandada hubiera cumplido la normativa reglamentaria habría evitado la disponibilidad del arma y el incremento del riesgo derivado de la posibilidad de utilización privada [...] Por consiguiente, ha habido la omisión de deber de cuidado que opera como contribución causal".

En la STS, Sala 1a , de 5 de noviembre de 2010 [RJ 2010183], el alto tribunal resuelve un caso en el que una persona menor con discapacidad se cae desde un puente durante una excursión organizada en el marco de las actividades de una granjaescuela. Se trataba de determinar si existía responsabilidad por omisión de los monitores. Nuevamente el TS aprecia primero que existe "negligencia" de los monitores que acompañaban a los menores, porque se había omitido una conducta debida, al "emprender la marcha el grupo de alumnos bajo la dirección de una sola

45 PANTALEÓN explica que la "causalidad" no empírica propia de las omisiones es una forma de imputación objetiva y menciona expresamente al criterio del incremento del riesgo; cfr. PANTALEÓN, Comentario del art. $1.902 \ldots$, p. 1984 y 1985. DÍEZ-PICAZO entiende que la regla del incremento del riesgo o la de la «conducta alternativa correcta» es "aplicable en los casos en que el evento dañoso se impute a una omisión" (DÍEZPICAZO, Derecho de daños..., p. 348. 
persona, cuando debían ser tres". A continuación aplica la fórmula de la conducta alternativa lícita para determinar si existe o no responsabilidad, considerando que: "el resultado dañoso sí fue causado por la conducta negligente de la monitora al no poder descartarse con seguridad o probabilidad rayana con la certeza que la presencia de los dos profesores del colegio con el grupo no habría impedido el daño".

\subsection{EL ARGUMENTO DE LA CONDUCTA ALTERNATIVA LÍCITA Y LA DOCTRINA DE LA PÉRDIDA DE OPORTUNIDADES}

En el apartado anterior se ha llegado a la conclusión de que la fórmula de la conducta alternativa lícita se emplea para determinar la peculiar "causalidad" no empírica de las omisiones, de manera idéntica a como se utiliza esa misma fórmula en el seno de la teoría de la imputación objetiva. Ahora bien, una cosa es que el argumento-y el razonamiento lógico-valorativo que encierra- sea el mismo, y otra distinta es que se apliquen del mismo modo. Existe un punto en el que las diferencias entre ambos mundos (el de la imputación objetiva y el de la causalidad en las omisiones) pueden llegar a ser importantes.

No debe olvidarse que, en el ámbito de la imputación objetiva, ya sabemos que el pretendido responsable ha causado positivamente el daño; mientras que en el de las omisiones ese supuesto responsable no ha hecho nada. Hemos visto que en la primera situación (cuando ya sé que el sujeto ha causado el daño), lo que se intenta comprobar mediante nuestro argumento es simplemente si con la conducta debida hubiera habido menos probabilidades de que sucediese lo mismo ${ }^{46}$. Sin embargo, en la segunda situación (cuando el sujeto se ha limitado a mantenerse estático, sin hacer lo que debía, y el daño se ha causado por circunstancias ajenas al mismo) ¿debe considerarse también suficiente para declarar la responsabilidad el hecho de que la conducta debida hubiese simplemente disminuido las probabilidades de que el daño se produjese? Y si es así, ¿qué alcance debe darse a esa responsabilidad?

En la jurisprudencia del TS en materia de omisiones podemos encontrar hasta tres respuestas distintas a estas preguntas:

Respuesta número uno. Frente a la alegación del argumento de la conducta alternativa lícita por parte del demandado, al demandante le basta con demostrar que la ejecución de la conducta debida hubiese disminuido el peligro de que el daño se produjese para obtener toda la indemnización.

Esta es la posición que el TS mantiene en las dos sentencias que he analizado al concluir el apartado precedente (5.1.). Leyendo estas dos resoluciones parece claro que, al alto tribunal le parece suficiente con probar que existían algunas probabilidades de evitar el peligro con la conducta debida (retirar la pistola al guardia jurado, añadir dos monitores más a la excursión), para declarar la responsabilidad de los demandados y condenarlos a reparar todo el daño que se reclama. Le basta, en un caso, con que el omitente haya aumentado el peligro "derivado de la posibilidad de utilización

46 En el caso de la ATS que suministra la dosis errónea de vacuna, busco comprobar si esa dosis errónea aumentó las probabilidades de que la menor falleciese. Si ello es así, si la acción negligente causante del daño 
privada" del arma, y en el otro con que «no pueda descartarse» que con los dos profesores adicionales se habría podido salvar al niño. En estas resoluciones el TS no se pregunta, respectivamente, ni si el guardia jurado habría causado la muerte por otros medios en caso de que se le hubiese retirado la pistola, ni tampoco qué probabilidades había de que el menor se cayese en caso de que hubiese dos monitores más. Por consiguiente, si quiere tener éxito, de conformidad con la doctrina de esas dos sentencias, el demandado que alega la excepción de "conducta alternativa lícita» tendría que probar que el hecho de realizar la conducta debida no habría aumentado en lo más mínimo la probabilidad de que el daño se produjese.

En esta primera respuesta, por lo tanto, el TS aplica un criterio de «todo o nada» ante la alegación del argumento de la conducta alternativa lícita por parte del demandado. En caso de que estime que la acción debida por el omitente habría reducido las probabilidades de que el daño se produjese procede condenarle a indemnizar todo el daño que se reclame, mientras que en caso contrario lo procedente es absolverle.

\begin{abstract}
Respuesta número dos. Frente a la alegación del argumento de la conducta alternativa lícita por parte del demandado, al demandante le basta con demostrar que la ejecución de la conducta debida hubiese disminuido el peligro de que el daño se produjese para obtener una indemnización proporcional-aproximadamente- a dicha disminución.
\end{abstract}

Esta tesis es la que mantiene el TS en los casos que califica como de «pérdida de oportunidad", fundamentalmente en el campo de la responsabilidad de los profesionales del derecho o de la medicina. En estos supuestos de pérdida de oportunidad (dejando ahora a un lado la cuestión del daño moral por la pérdida de oportunidad en sí misma considerada), estamos exactamente ante la misma situación a la que se enfrentaba el TS en las dos sentencias que hemos comentado sub respuesta núm. 1: el demandado omite una conducta debida que el demandante entiende que podía haber evitado el daño. Sin embargo, pese a que la situación es idéntica a la de esos dos casos anteriores, la solución que actualmente suele darles el TS a los casos de pérdida de oportunidad es sustancialmente diversa. Mientras que en los dos asuntos anteriores la apreciación de que con la conducta debida habrían aumentado las probabilidades de que el perjuicio se evitase es suficiente para conceder la totalidad de la indemnización, en los casos que el TS cataloga como de "pérdida de oportunidad" lo que sucede lo explica con meridiana claridad el propio TS en su STS de 27 julio de 2006 [RJ 200616548]:

"[...] la valoración de la pérdida de oportunidades de carácter pecuniario abre un abanico que abarca desde la fijación de una indemnización equivalente al importe económico del bien o derecho reclamado, en el caso de que hubiera sido razonablemente segura la estimación de la acción, hasta la negación de toda indemnización en el caso de que un juicio razonable incline a pensar que la acción era manifiestamente infundada o presentaba obstáculos imposibles de superar y, en consecuencia, nunca hubiera podido prosperar en condiciones de normal previsibilidad".

(de la que parto) era más peligrosa que la alternativa diligente -porque tenía más probabilidades de causar el 
Por consiguiente, al TS, aunque para entender acreditada la "causalidad" en relación las omisiones de los profesionales del derecho o de la medicina, le sigue bastando con que la hipotética conducta conforme a la lex artis (la presentación del recurso, la emisión del diagnóstico de modo tempestivo, etc.) hubiese reducido la probabilidad del daño, esa "causalidad" ya no dará lugar a una indemnización completa. Por el contrario, en estos casos el Supremo mantiene que la indemnización debe ser proporcional a la probabilidad de que el daño se evitase (el abanico de posibilidades al que se refiere la sentencia transcrita).

Así, en unos casos, el TS concede toda la indemnización, porque entiende que la probabilidad de que la conducta alternativa lícita evitase el daño es muy elevada. Esto sucedió, por ejemplo, en el asunto resuelto por la STS, Sala 3 $3^{\text {a }}$, de 25 junio 2010 [RJ 2010\5886], en el que unos padres demandan al servicio público de salud alegando que el médico no les había advertido de la insuficiencia de la vacuna que se había inoculado a su hijo años antes, a resultas de lo cual el niño no pudo protegerse frente a la meningitis que produjo su muerte. En otras situaciones, sin embargo, como la de la STS de 2 enero 2012 [RJ 2012\2], en la que se demanda al servicio público de salud por no haber diagnosticado el médico un cáncer meses antes de que se descubriese en el paciente, la indemnización se limita "en razón de la probabilidad de que el daño se hubiera producido, igualmente, de haberse actuado"47.

Esta misma doctrina jurisprudencial se aplica a los casos de responsabilidad médica en la que el daño se intenta atribuir a la omisión de información sobre los riesgos de una intervención médica. Me refiero a los supuestos en los que un facultativo omite su deber de obtener el denominado "consentimiento informado". La relevancia causal que se atribuye a esa omisión y sus consecuencias están perfectamente resumidas en la STS de 8 abril de 2016 [RJ 201611328]:

\begin{abstract}
"Tanto esta Sala de la jurisdicción civil como la de la contencioso-administrativo del TS se ha ocupado de la omisión o deficiencia del consentimiento informado como una mala praxis formal del facultativo, en la que la relación de causalidad se establece entre la omisión de la información y la posibilidad de haber eludido, rehusado o demorado el paciente la intervención médica cuyos riesgos se han materializado.

Se ha venido distinguiendo entre supuestos en los que, de haber existido información previa adecuada, la decisión del paciente no hubiese variado y, en principio, no habría lugar a indemnización (STS 29 de junio de 2007 (RJ 2007, 3871 ), sin perjuicio de que en ciertas circunstancias, se pudiese determinar la existencia de un daño moral, de aquellos otros en que, de haber existido información previa adecuada, la decisión del paciente hubiese sido negarse a la intervención, por lo que, al no existir incertidumbre causal, se concede la indemnización íntegra del perjuicio que se ha materializado ( SSTS 23 de abril de 1992 (RJ 1992, 3323); 26 de septiembre de 2000; 2 de julio de 2002 (RJ 2002, 5514); 21 de octubre de 2005 ). Así viene a reconocerlo la sentencia que se cita por el recurrente de 4 de marzo de 2011.

Cuando no existe incertidumbre causal en los términos extremos antes expuestos, surge la teoría de la pérdida de oportunidad [...] en las que no se identifica necesariamente con la gravedad y trascendencia del daño, sino con una fracción del
\end{abstract}

daño-, entonces la ATS debe ser considerada responsable de la muerte.

47 Ejemplos similares, pero en el ámbito de la responsabilidad de los profesionales del derecho podrían multiplicarse. En estos casos, el TS aplica la doctrina del "juicio dentro del juicio" para valorar las posibilidades de éxito de la acción judicial frustrada por la omisión del abogado e indemniza en función de dichas probabilidades; cfr. v.gr. SSTS de 28 de febrero de 2008 [RJ 2008\4035], de 22 abril de 2013 [RJ 201313690], de 5 de junio de 2013 [RJ 2013\4971]. 
daño corporal considerado en su integridad en razón a una evidente incertidumbre causal sobre el resultado final"48.

En definitiva, se abre en estos supuestos de omisión de información sobre los riesgos de una intervención el mismo «abanico» de posibilidades que hemos visto que, según la STS de 27 julio de 2006 [RJ 200616548], se abría en los casos de responsabilidad de los profesionales del derecho que omiten la presentación de una demanda, recurso o el ejercicio de algún tipo de acto jurídico en un plazo de caducidad o preclusión. Si la conducta debida hubiese conducido a una situación en la que era altamente probable que el paciente se hubiese negado a la intervención, procede la indemnización íntegra. $\mathrm{Si}$, por el contrario, lo razonable es pensar que la decisión de paciente no hubiese variado, entonces no cabe conceder indemnización alguna. Por último, si las probabilidades se sitúan entre la primera y la segunda situación, lo que debe hacerse es dar una indemnización proporcional a esas probabilidades.

Respuesta número tres. No cabe la alegación del argumento de la conducta alternativa lícita porque la relevancia de la omisión a la que se pretende atribuir responsabilidad se prueba por sí sola.

Finalmente, existe un tipo de casos en los que el TS, en la práctica, no admite la alegación del argumento de la conducta alternativa lícita. Curiosamente estos casos son los mismos en los que MARTÍN-CASALS y SOLÉ propusieron aplicar por primera vez este argumento en relación con la "causalidad" de las omisiones. Me refiero, claro está, a los casos de wrongful birth. En estos supuestos, tras un primer momento en el que el TS aplicó la misma doctrina que acabamos de exponer en la respuesta número 2, haciendo depender la procedencia de su indemnización y el montante de lo que presumiblemente hubiese hecho la madre si se le hubiese informado de la malformación del feto, cambió su jurisprudencia ${ }^{49}$. Seguramente, ejercieron una notable influencia en este cambio de parecer las críticas recibidas por parte de autores como BERCOVITZ, que denunció la posición jurisprudencial como un juicio basado "en apriorismos carentes de razonabilidad", a partir de "la actitud previa existencial, ideológica o religiosa, o las circunstancias familiares, sociales y materiales" de la madre. Las críticas apuntaban a que: "nadie puede afirmar en principio cuál sería la reacción de una persona ante semejante dilema"50.

Así, a partir de la STS de 21 de diciembre de 2005 [RJ 2005\10149], el tribunal reacciona y rechaza la alegación del argumento de la conducta alternativa lícita. En esta nueva jurisprudencia es el propio "hecho de haberse sometido a una prueba para el diagnóstico prenatal" de malformaciones el que demuestra que existían probabilidades suficientes de que la madre optase por un aborto, dado que estas pruebas "sólo tienen un sentido lógico que es el de decidir en su vista esta interrupción voluntaria del embarazo". Para el TS, en estos casos, res ipsa loquitur: si la madre se sometió a una

48 En el mismo sentido, además de las resoluciones citadas en el extracto, vid. SSTS de 28 de noviembre de 2007 [RJ 2007, 8428] y 23 de octubre de 2008 [RJ 2008, 5789].

49 Cfr. STS de 7 de junio de 2002 [RJ 200215216]. En esta sentencia, el TS confirma la sentencia de instancia que desestima la acción de responsabilidad porque constaba en autos que: "la señora $R$. en ningún momento quiso abortar". 
prueba de detección de malformaciones es porque existía una probabilidad suficiente de que abortase. Lo demás, según el alto tribunal, es "un debate estéril fundado en simples y absurdas especulaciones" 51 . Así pues, para el tribunal supremo, en los casos de wrongful birth, el argumento de la conducta alternativa lícita no es relevante, ya que la realización de la propia prueba diagnóstica que da lugar a la omisión revela que existía una probabilidad bastante de que la madre solicitase la práctica el aborto.

Vistas las tres respuestas diversas que la jurisprudencia ha dado a la cuestión de la conducta alternativa lícita en el mundo de la responsabilidad por omisiones, tiene todo el sentido preguntarse ¿está justificada esta diversidad de trato? ¿Por qué a algunos casos se le aplica la doctrina del «todo o nada» (primera respuesta), mientras que a otros (segunda respuesta) se les asigna una indemnización en función de las probabilidades que había de evitar el daño con la conducta correcta? ¿De verdad es distinto el caso de wrongful birth de los otros dos anteriores?

Creo que la respuesta a todas estas preguntas pasa en primer término por recordar un hecho fundamental: ontológicamente no hay diferencia alguna entre las distintas omisiones que hemos considerado en los tres grupos de casos. En todos ellos hay alguien que ha omitido un comportamiento debido (es decir, una conducta que le imponía el affirmative duty que le afectaba o la posición de garante que ocupaba). El demandado tenía el deber de actuar de un determinado modo que podía haber evitado el daño. Podría pensarse que esta omisión en distinta en las pérdidas de oportunidad que en los supuestos del primer grupo, pero esto es pura semántica. Si queremos que así sea, podemos presentar todos los supuestos que hemos analizado como casos de pérdida de oportunidad. Para convertir un caso del grupo primero en una pérdida de oportunidad basta con cambiar la forma de contarlo y decir: a) que a la víctima del disparo se le privó de la oportunidad que tenía de sobrevivir si se hubiese recogido el arma de fuego del guardia de seguridad, o b) que al menor que se cayó del puente se le privó de la oportunidad de ser salvado por los dos monitores que debían haber estado allí presentes.

Por otra parte, es evidente que cualquiera de los casos que hemos visto en cada uno de los tres grupos es susceptible de ser solventado indistintamente aplicando la doctrina del todo o nada, o la de la indemnización en función de las probabilidades. Los casos del primer grupo podrían haberse resuelto indemnizando a la familia de la víctima del guardia de seguridad o a la del menor que se cae del puente, con una cantidad proporcional a la probabilidad que existía de que la conducta debida evitase el daño. Igualmente, todos los casos de pérdida de oportunidad podrían resolverse como los del primer grupo: en caso de que se demostrase que existía una probabilidad significativa de evitar el daño se concedería la reparación completa, y nada en el caso contrario ${ }^{52}$. Por lo demás, es indudable

${ }^{50}$ Cfr. BERCOVITZ RODRíGUEZ-CANO, R: Comentario a la STS de 7 de junio de 2002. CCJC, n. 59, abr.-sep. 2002. p. 857 y ss.

51 La misma doctrina es recogida en casos de wrongful birth en las SSTS de 24 octubre de 2008 [RJ 200815793] y de 4 de noviembre de 2010 [RJ 201017988]; así como. v.gr. en la SAP de Salamanca (Sección 1ª̂) de 29 noviembre de 2006 [JUR 2007\194526].

52 De hecho Pasquau, por ejemplo, ha manifestado que, en su opinión, esta sería la solución correcta para los casos de omisión del deber de información del médico, dado que, en su opinión, en estos casos es "como si el facultativo decidiera por el paciente", por lo que debe ser él el que asuma el riesgo de la operación, cfr. PASQUAU, Valoración crítica..., p. 491. 
que los supuestos de wrongful birth pueden también resolverse aplicando cualquiera de los criterios anteriores.

No existiendo ninguna diferencia ontológica o cualitativa entre los tres grupos de casos anteriores, resulta bastante claro que la diversidad de soluciones que el TS ha dado a estos supuestos se debe a cuestiones de equidad, de política jurídica o de orden práctico. Es difícil, sin embargo, conocer cuáles son las verdaderas razones por las que la jurisprudencia decide de modo diverso los casos del primero y del segundo grupo. Es posible que haya pesado la idea de que la expansión de la responsabilidad médica encarece los servicios sanitarios y dificulta el mantenimiento del sistema, y se haya querido aliviar al sector de la carga de soportar la indemnización completa en los supuestos calificados como pérdidas de oportunidad. Es también posible que el TS se sienta más cómodo calculando las probabilidades de que una acción judicial o un recurso de apelación prospere o no prospere (mediante el «juicio dentro del juicio»), de lo que se siente haciendo lo mismo con la caída de un menor desde un puente cuando faltaban dos monitores. Pero todo esto son meras ideas que se me ocurren de cuya veracidad no tengo la más mínima prueba.

En los casos de wrongful birth, sin embargo, parece más claro que el TS lo que ha querido es directamente no permitir el juego del argumento de la conducta alternativa lícita, al conducir esta fórmula -necesariamente- a valorar una cuestión tan espinosa -y tan intrínsecamente relacionada con derechos fundamentales y principios constitucionales (como el libre desarrollo de la personalidad o la libertad ideológica)- como los motivos que conducen a una mujer a abortar. Al margen que sea o no comprensible y compartible lo que ha decidido el TS en estos casos, lo que es evidente es que, en la realidad de las cosas, llegar a conocer lo que una mujer podría haber decidido en caso de que se le hubiese informado sobre la malformaciones del feto que está gestando, pertenece al mismo orden de cuestiones que la consistente, por ejemplo, en valorar lo hubiera decidido un paciente de conocer los riesgos de una intervención médica.

\section{EL ARGUMENTO DE LA CONDUCTA ALTERNATIVA LÍCITA COMO INSTRUMENTO PARA NEGAR LA CAUSALIDAD DE LAS ACCIONES}

La tercera y última de las situaciones en las que, desde el principio de este trabajo, he dicho que puede aparecer el argumento de la conducta alternativa conforme a derecho es aquella en la que el demandado trata de negar la existencia de relación de causalidad entre su conducta activa -entre la acción que ha realizado- y el daño. Esta era la situación que contemplábamos en el caso de responsabilidad por daños derivados de una infracción de la libre competencia. En el caso C) del primer apartado, los integrantes del cártel de compras demandado se defendían alegando que la conducta infractora que se les achacaba no guardaba relación alguna con las pérdidas de la demandante, la empresa Addamax. Para ello alegaban que, aun cuando no hubiesen conformado un cártel, el producto ofrecido por Addamax no se hubiese vendido igualmente porque era demasiado caro y sofisticado. 
La situación ante la que nos encontramos en este caso es similar con la que analizamos en el apartado dedicado a la imputación objetiva, pero también existen importantes diferencias entre ellas. En ambos casos el demandado que alega el argumento de la conducta alternativa lícita pretende demostrar que lo ilícito de su comportamiento (su infracción de los deberes de conducta que le atañían) no es lo que ha provocado el daño cuyo resarcimiento se le reclama. Sin embargo, en el marco de la imputación objetiva, el demandado asume que ha provocado el daño, sólo que mantiene que éste no es la consecuencia de su falta de diligencia (el médico que se defiende argumentando que la novocaína hubiese matado igual al paciente, parte del hecho de que la muerte la provocó la anestesia que él le suministró). Por el contrario, aquí, el demandado que usa el argumento que nos ocupa quiere justificar que él no causó el daño, sino que hubo otra causa distinta de su propia conducta que lo produjo (lo que dicen los cartelistas es que el daño no lo causaron ellos, sino los propios defectos del producto ofertado por Addamax).

Esta diferencia esencial se traduce en que, en los casos que ahora estoy analizando, a diferencia de lo que sucede en los de imputación objetiva, el demandado que usa el argumento tiene que alegar y probar la causa a la que entiende que debe atribuirse realmente el daño. En el asunto de los daños reclamados por Addamax, los cartelistas no pueden limitarse a alegar que su conducta infractora es inocua, sino que además tienen que alegar y probar que las pérdidas de Addamax se debieron a lo excesivamente caro y sofisticado que era su software de seguridad. En el fondo, de lo que se trata aquí no es de que el demandado demuestre que la ilicitud de su conducta era irrelevante, sino que esa conducta en sí misma -al margen de su ilicitud o licitud- no es la causa material del daño. Es por este motivo por lo que es necesario darle al juez un segundo elemento esencial para que se pueda producir la exoneración de responsabilidad: la verdadera causa del daño cuya reparación se pide.

En realidad, cuando se emplea el argumento de la conducta alternativa conforme a derecho de la manera que se acaba de exponer, se está empleando de un modo impropio. En las dos situaciones que hemos analizado con anterioridad, la finalidad del argumento era demostrar la irrelevancia del incumplimiento del deber de cuidado en que había incurrido el demandado, a) bien dentro de una cadena causal iniciada por el demandado o en la que este había participado activamente (en los casos de imputación objetiva), b) o bien en el marco de un curso causal en el que el demandado estaba obligado a intervenir (en la responsabilidad por omisiones). En el caso que ahora estamos analizando, sin embargo, lo único que quiere demostrar el demandado es que fue otra causa distinta de su acción la que causó el daño. Por esta razón, es natural que REGLERO, cuando se refiere a este modo de interpretar el criterio del incremento del riesgo, lo identifique con la "but for» rule ${ }^{53}$ o, lo que es lo mismo, con la fórmula de la condicio sine qua non: lo que persigue el demandado en estos casos es demostrar que, suprimida su conducta (da igual que sea lícita o ilícita), el daño se habría ocasionado igualmente.

Tratándose de un simple modo de expresar lo mismo que la fórmula de la condicio sine qua non, cabe preguntarse si tiene algún sentido emplear el argumento de la conducta alternativa lícita en

${ }^{53}$ Cfr. REGLERO, Tratado de responsabilidad civil..., pp. 357-359. 
este ámbito. A mi modo de ver, si lo tiene, es por razones de mera estrategia procesal: se trataría de una manera de intentar centrar la atención del juez en el problema causal, en la determinación de quién o qué es lo que ha causado materialmente el perjuicio que se reclama, sin mezclar indebidamente esta cuestión con la de la eventual negligencia o ilicitud del demandado. Es una forma de decirle al juez: señoría, asumamos que mi cliente ha cometido una infracción -o que ha actuado en contra del deber de diligencia que le incumbía-; verá que en este caso eso es indiferente, lo importante es que el daño ha sido debido a otra circunstancia totalmente distinta. Más allá de este fin «práctico» de intentar que el debate procesal no se centre en la infracción de unos deberes de conducta que son irrelevantes, no veo que tenga mayor interés como argumento jurídico.

\section{CONCLUSIONES}

I. El argumento de la conducta alternativa lícita o de la conducta alternativa conforme a derecho se emplea, en el ámbito del derecho de daños, en una multiplicidad de situaciones calificables dogmáticamente como de falta de causalidad o de falta de imputación objetiva, o incluso de pérdida de oportunidad.

II. El argumento de la conducta alternativa lícita aparece en la doctrina penal alemana a principios del siglo XX. Después de un desarrollo de varias décadas, en el momento actual, la doctrina penal alemana y española, además de la jurisprudencia, estiman que este argumento sirve para que un acusado quede exonerado de responsabilidad por falta de imputación objetiva.

III. En la práctica, en sede penal, el acusado que emplea el argumento de la conducta alternativa lícita debe demostrar que había -aproximadamente- las mismas probabilidades de que el resultado prohibido por el tipo delictivo se produjese con su conducta imprudente que con una conforme con el deber de cuidado o diligencia.

IV. La importación al derecho de daños español del argumento de la conducta alternativa lícita se produce por dos vías: a través de la doctrina que propone incorporar a nuestro derecho la imputación objetiva desde el derecho penal alemán, y a través de la doctrina que emplea obras de especialistas alemanes en derecho de daños, los cuales suelen ver al argumento como un mecanismo para resolver problemas de causalidad material.

V. Dentro de la teoría de la imputación objetiva, que el TS emplea para determinar qué causas son relevantes dentro de todos los antecedentes causales de un daño, el argumento de la conducta alternativa lícita constituye una versión del conocido criterio del incremento del riesgo.

VI. El argumento de la conducta alternativa lícita, cuando se emplea para resolver un problema de imputación objetiva, permite que el demandado se exonere de responsabilidad cuando pueda probar que, pese a haberse comportado de modo negligente, esa falta de diligencia suya no ha incrementado el riesgo de que se produjese el daño que se reclama.

VII. Para que la alegación del argumento de la conducta alternativa lícita, empleado como medio para excluir la responsabilidad por falta de imputación objetiva, tenga éxito no basta con demostrar que el daño podía haberse producido también con un comportamiento diligente. Es 
necesario probar que las probabilidades de que se produjese en ese caso eran sustancialmente las mismas que con la conducta negligente desplegada por el demandado. De otro modo, debe entenderse que la conducta del demandado ha incrementado el riesgo de que se produjese el daño y, por tanto, acreditada la existencia de nexo causal.

VIII. El argumento de la conducta alternativa lícita se usa también para valorar si pueden estimarse la existencia de causalidad en las omisiones. En concreto, este argumento permite excluir la presencia de relación de causalidad cuando el deber de actuar que el derecho le imponía al demandado, y que éste omitió, no hubiese impedido que el daño se produjese igualmente y con idéntica extensión.

IX. En un caso de responsabilidad por omisiones, será ineficaz el argumento de la conducta alternativa lícita siempre que quede acreditado que, de haber realizado el demandado la conducta debida, habría disminuido la probabilidad de que el daño se produjese.

X. En la responsabilidad por omisiones, las consecuencias jurídicas atribuibles a la prueba de que la probabilidad del daño habría disminuido de haberse ejecutado la conducta debida dependen del tipo de caso ante el que nos encontremos: a) si se trata de un caso de pérdida de oportunidad, el demandado será condenado a indemnizar el daño en proporción a la disminución de la probabilidad; b) si se trata de un caso al que no se aplica la doctrina de la pérdida de oportunidad el demandado deberá indemnizar todo el daño.

XII. En los casos de wrongful birth la jurisprudencia ha vedado la alegación del argumento de la conducta alternativa lícita, debido a consideraciones de carácter valorativo.

XIII. El argumento de la conducta alternativa lícita sólo puede emplearse en un sentido impropio, si lo que se pretende es demostrar que una determinada acción o actividad no ha sido la causa material de un daño. En estos casos, el argumento de la conducta alternativa lícita se confunde con la fórmula de la condicio sine qua non y exige que el demandado que la alega pruebe cuál fue la verdadera causa del perjuicio.

\section{BIBLIOGRAFÍA}

ATAZ LÓPEZ, J.: Quince años de jurisprudencia civil y administrativa en materia de daños. En: HERRADOR, M. (dir.): Daño, Responsabilidad y Seguro. Madrid: Francis Lefebvre, 2016.

BERCOVITZ RODRÍGUEZ-CANO, R: Comentario a la STS de 7 de junio de 2002. CCJC, n. 59, abr.sep. 2002.

DE ÁNGEL, Causalidad en la responsabilidad extracontractual: sobre el arbitrio judicial, la «imputación objetiva» y otros extremos. Madrid: Cívitas, 2014.

DÍEZ-PICAZO Y PONCE DE LEÓN, L.: Derecho de daños. Madrid: Cívitas, 2000.

GARCíA AMADO, J.A.: Sobre algunos mitos del derecho de daños. Causas que no causan e imputaciones objetivas bastante subjetivas. En: HERRADOR, M. (Dir.): Derecho de daños 2013. Cizur Menor: Thomson Reuters-Aranzadi, 2013. 
GIMBERNAT, E.: El comportamiento alternativo conforme a derecho. De la causalidad a la imputación objetiva. Montevideo-Buenos Aires: B. de F., 2017.

JESCHECK, H-H.: Tratado de Derecho penal. Parte General. Traducción de la 5. ed. alemana de 1996. Granada: Comares, 2002.

KOZIOL, H.: Austrian report. En: SPIER, J. (edit.): Unification of Tort Law: Causation. London: Kluwer Law International, 2000.

KOZIOL, H.: Basic Questions on Tort Law from a Germanic Perspective. Viena: Jan Sramek Verlag, 2012.

MARKESINIS, B.; UNBERATH, H.: The German Law of Torts. A Comparative Treatise. Oxford: Hart Publishing, 2002.

MARTÍN CASALS, M.: La modernización del derecho de la responsabilidad extracontractual. En: AA.VV. Cuestiones actuales en materia de responsabilidad civil. XV Jornadas de la APDC. Servicio de publicaciones de la Universidad de Murcia. Murcia, 2011.

MARTíN CASALS, M., SOLÉ, J.: Responsabilidad civil por la privación del derecho a abortar (wrongful birth). Indret, 2/2004, 2004.

MEDINA ALCOZ, L., El nexo causal. La pérdida de oportunidad. En: REGLERO, F.: Tratado de responsabilidad civil. Cizur Menor: Thomson Reuters-Aranzadi, 2014, t. I.

PACHECO JIMÉNEZ, Ma ${ }^{a}$ N.: Responsabilidad médica derivada de negligencia en el diagnóstico prenatal: acciones wrongful birth y wrongful life. Repercusión de la proyectada ley de protección de la vida del concebido. En: Anuario Parlamento y Constitución, n. 15, 2012-2013, p. 287-308.

PANTALEÓN PRIETO, F.: Comentario del artículo 1.902 del Código Civil. En: AA.VV.: Comentario del Código Civil. Madrid: Ministerio de Justicia, 1991, t. II.

PAÑOS PÉREZ, A.: Responsabilidad civil médica por wrongful birth y wrongful life. En: Diario La Ley, n. 8396, sección doctrina, 10 oct. 2014.

PEÑA LÓPEZ, Dogma y realidad del derecho de daños: imputación objetiva, causalidad y culpa en el sistema español y en los PETL. Cizur Menor: Thomson Reuters-Aranzadi, 2011.

PASQUAU LIAÑO, M.: Valoración crítica de la aplicación jurisprudencial de la doctrina de la pérdida de oportunidades. En: HERRADOR, M. (dir.): Daño, Responsabilidad y Seguro. Madrid: Francis Lefebvre, 2016.

REGLERO CAMPOS, L.F. (Coord.). Tratado de Responsabilidad Civil, 3. ed. Cizur Menor: Thomson Reuters-Aranzadi, 2006.

ROMERO COLOMA, A.Mㄹ.: Las acciones de wrongful birth y wrongful life en el Ordenamiento Jurídico español (especial referencia a la responsabilidad civil médica). Revista Crítica de Derecho Inmobiliario, n. 722 2010, p. 2559 a 2608.

ROXIN, C.: Derecho Penal. Parte General. Fundamentos. La estructura de la teoría general del delito. Traducción de la edic. alemana de 1994. Madrid: Cívitas, 1998, t. I.

SALVADOR CODERCH, P.: «Causalidad y responsabilidad». InDret, v. 1, p. 1-27, 2000.

VAN DAM, C.: European Tort Law. 2. ed. Oxford: Oxford University Press, 2013.

VON BAR, Ch.: The Common European Law of Torts. Oxford: Oxford University Press, 2005, v. 2. 
YZQUIERDO TOLSADA, M. Responsabilidad civil extracontractual: Parte General. Madrid: Dydinson. 2015.

Como citar: PEÑA LÓPEZ, Fernando. El argumento de la "conducta alternativa lícita" en el derecho de daños. Revista IBERC, Minas Gerais, v. 2, n. 3, p. 1-30, set./dez. 2019. 